Article

\title{
Experimental and Numerical Analysis of Mixed I-214 Poplar/Pinus Sylvestris Laminated Timber Subjected to Bending Loadings
}

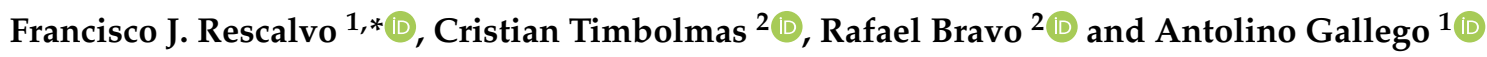 \\ 1 Building Engineering School, University of Granada, 18071 Granada, Spain; antolino@ugr.es \\ 2 Department of Structural Mechanics, University of Granada, 18071 Granada, Spain; timbolmas@ugr.es (C.T.); \\ rbravo@ugr.es (R.B.) \\ * Correspondence: rescalvo@ugr.es; Tel.: +34-665177795
}

Received: 31 May 2020; Accepted: 13 July 2020; Published: 14 July 2020

check for updates

\begin{abstract}
The structural use of timber coming from fast growing and low-grade species such as poplar is one of the current challenges in the wood value chains, through the development of engineering products. In this work, a qualitative comparison of the behavior of mixed glued laminated timber made of pine in their outer layers and of poplar in their inner layers is shown and discussed. Single-species poplar and pine laminated timber have been used as control layouts. The investigation includes destructive four-point bending tests and three non-destructive methodologies: finite elements numerical model; semi-analytical model based on the Parallel Axes theorem and acoustic resonance testing. An excellent agreement between experimental and numerical results is obtained. Although few number of samples have been tested, the results indicate that the use of poplar as a low-grade species in the inner layers of the laminated timber can be a promising technology to decrease the weight of the timber maintaining the good mechanical properties of pine. Likewise, the need for the use of the shear modulus in both experimental measurements and numerical analysis is suggested, as well as the need to reformulate the vibration methodology for non-destructive grading in the case of mixed timber.
\end{abstract}

Keywords: poplar; pine; timber; glulam; bending; numerical modelling; non-destructive testing

\section{Introduction}

The development of Engineered Wood Products (EWP) such as glued laminated timber or Glulam [1-5] enhance the use of wood with a wider range of benefits: (1) greater dimensional stability; (2) higher design flexibility, allowing timber to be produced in a wide variety of shapes from straight beams to curved arches. This fact offers a multitude of options for large and open spaces with a reduced number of columns; (3) cover longer span lengths and cross-sections, thus being a product of a huge variety of uses, from residential constructions up to commercial buildings and timber bridges where higher structural requirements are needed; (4) higher quality of the final product due to the grading of the planks, a selection according to their stiffness and mechanical properties and the removal of knots and another undesirable defects; (5) the use of a wood species with lower diameters when compared with sawn timber; (6) the use of lower-grade timber in lower-stress zones, resulting in a more efficient use and conservation of the timber resources. Regarding the last two benefits, poplar (populus) is one of the better candidates to be used for glulam timber. In Spain, poplar (Populus x aeuroamericana (Dode) Guinier) is one of the most important plantation species, covering an extension of 145,000 ha approximately according to FAO [6,7]. Currently the use of poplar is mainly used for peeling and plywood manufacturing. The development of EWPs and its use for structural purposes is a huge opportunity to develop all the wood value chain. 
Combination of different wood species has a wide range of structural advantages being introduced by Biblis [8]. In [9], the authors developed a theoretical analysis and performed an evaluation by means of twenty large beams graded visually and made of Douglas-fir (Pseudotsuga menziesii) and lodgepole pine (Pinus contorta). Results demonstrate that the low-grade wood, i.e., lodgepole, with similar mechanical properties than poplar, used in the inner part of the glulam beams, had a little effect on the general mechanical properties. Previous works studied the mechanical properties of poplar glulam beams $[10,11]$. In particular, Martins and collaborators used this grade consideration to sort the plank for every glulam beam by using the longitudinal vibration method (LVM) [11]. That work correlates the non-destructive testing with the mechanical properties of poplar glulam beams considering 4 types of adhesives. Authors also compare the results with the transform section method (TSM) calculated by using the modulus of elasticity of each plank. Results demonstrate a very good performance between TSM method and the global modulus of elasticity, with a correlation coefficient of 0.93 , and a good correlation of 0.8 between LVM method and the global modulus of elasticity. A comparison between single-species glulam poplar (Neva clone, with a low density) and eucalyptus beams and mixed beams by using four types of eucalyptus clones was performed by Castro et al. [12]. For the grading of the planks, they performed a quasi-nondestructive static bending test applying low loads to them. Mixed beams designs consisted in five inner poplar planks and two outer eucalyptus planks. In general terms, results demonstrate that the combination of species and the use of the low-grade species in the inner part of the glulam timber enhance the modulus of elasticity between $9 \%$ and $51 \%$ depending on the eucalyptus clone. To evaluate the ductile behavior of mixed glued laminated timber, the authors of [13] also considered poplar for the inner part of the beams, mainly due to its low density and good shear performance, using Norway spruce and larch wood for the outer planks. In addition, authors evaluated the mechanical behavior elaborating glulam timber from the same wooden species but different strength classes (as Hernandez and collaborators proposed for poplar glulam timber [14]). Results demonstrate that combination of species results more efficient when they have clearly different strength limits between them. Authors also remarked the high importance of an accurately grading of the planks during the design process. In [15-17], the authors also combined different species of wood with the same final conclusion of low-grade, high-grade timber distribution for inner and outer parts of the glulam timber, respectively. Furthermore, this conclusion has been recently extended to CLT (Cross Laminated Timber) panels [18]. In [16], when a high-grade wood such as Merpauh was used for the outer planks, improvements of the modulus of elasticity between $117 \%$ and $157 \%$ were achieved.

An improvement method in [19] was presented by Shin et al., taking into account the neutral axis shifts in bending using the Time-of-Flight method. Authors took into account the differences between compression and tensile modulus of elasticity, improving the relationship between static and dynamic elastic moduli. Despite taking into account the neutral fiber axis shifts, results from previous works $[20,21]$ for sawn timber, demonstrate that resonance method results in a more reliable technique to obtain the dynamic modulus of elasticity, since this method consider the whole piece of wood. Finite Element Method is powerful tool to predict the elastoplastic behavior of natural beams with flaws, as knots and grain deviation in bending [22]. It can reproduce with a good accuracy the four-point bending tests laminated beams (see, e.g., the application of FEM (Finite Element Method) to Cathay poplar glulam beams in [23]).

In order to qualitatively assess the behavior of a mixed glulam timber using poplar wood for the inner part and pine for the outer layers, three layouts have been tested in this work: (1) single-species pine timber used as control specimens; (2) single-species poplar timber used as control specimens; (3) mixed poplar/pine timber. To ensure a good performance and a proper sample design, all the planks were graded individually by means of the resonance acoustic testing. Subsequently, the samples were subjected to a four-point bending test following the standard [24], and the results were compared with three non-destructive methodologies: (1) numerical finite elements model (FEM); (2) Parallel Axes theorem; (3) acoustic resonance testing (ART). All the samples were graded and compared according the standard and an analysis of the effectiveness of the use of poplar for the inner layers has been carried 
out. Due to the low number of samples used for each timber layout, the results of this work should be considered only in qualitative and not in quantitative terms. In any case, since the main objective of this work is to compare the proposed numerical method with the experiments, the results make it clear that after calibration and using the shear modulus in the formulation, an excellent agreement is obtained between numerical and experimental results.

\section{Materials and Methods}

\subsection{Experimental Program Flow}

The experimental program followed the chart flow shown in Figure 1. Poplar and pine planks used for the glulam timber samples were graded according with their dynamic modulus of elasticidity, $\mathrm{MoE}_{\mathrm{dyn}, \mathrm{p}}$, obtained by Acoustic Resonance Testing (ART). Based on this grading, design and then manufacturing of the laminated timber were carried out. After that, timber was subjected to ART in order to obtain their dynamic modulus of elasticity, $\mathrm{MoE}_{\mathrm{dyn}, \mathrm{gt}}$. Finally, they were destructively tested in bending, thus obtaining their static modulus $\mathrm{MoE}_{\text {st }}$ and the maximum stress in bending, $\sigma_{\max }$.

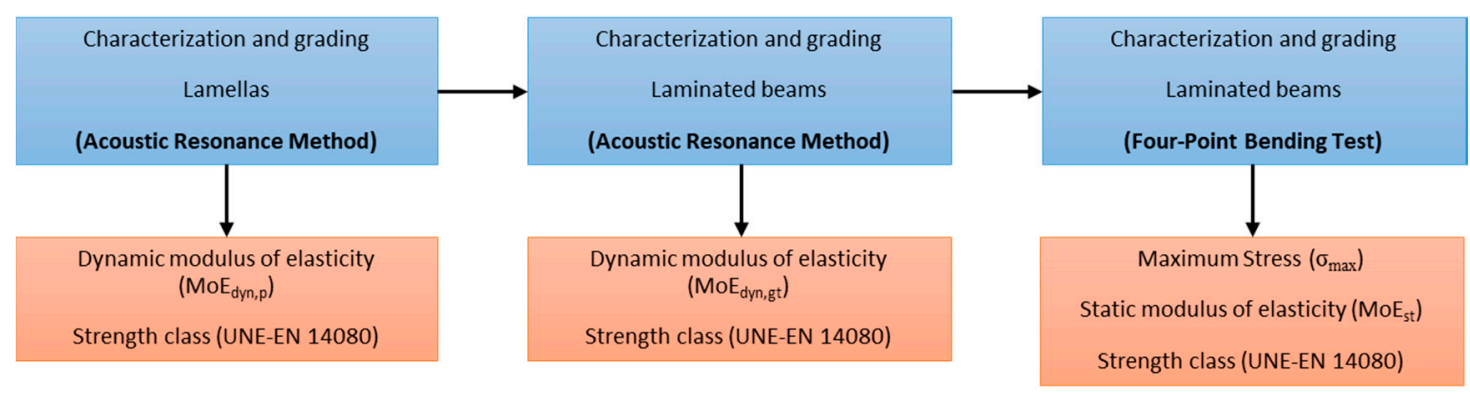

Figure 1. Chart flow of the general experimental procedure. $\mathrm{MoE}_{\mathrm{dyn}, \mathrm{p}}$ : Dynamic modulus of elasticity of planks. $\mathrm{MoE}_{\mathrm{dyn}, \mathrm{gt}}$ : Dynamic modulus of elasticity of glulam timber. omax: Maximum stress in bending. $\mathrm{MoE}_{\mathrm{st}}$ : Static modulus of elasticity.

\subsection{Raw Material and Planks}

Two species were used, Pinus sylvestris and poplar clone I-214 (Populus x aeuroamericana (Dode) Guinier). Thirty-four pine planks were extracted from the same sawn timber batch at 90 years old forests of Soria province (Spain), supplied by Madera Pinosoria S.L. Similarly, 14 poplar planks were extracted from the same sawn timber batch from a 13 years old poplar plantation located at Yunquera de Henares (Guadalajara, Spain). Both pine and poplar timber were artificially dried, ensuring a final moisture content (MC) of $12 \%$. Planks had a cross-section of $20 \times 50 \mathrm{~mm}^{2}$ and a total length of $1240 \mathrm{~mm}$. The mean density at $\mathrm{MC}=12 \%$ for the pine and poplar planks was of $526 \pm 55$ and $347.3 \pm 22.7 \mathrm{~g} / \mathrm{cm}^{3}$, respectively.

\subsection{Dynamic Modulus of Elasticity of Planks: Acoustic Resonance Testing}

All the planks were subjected to an ART $[20,21]$ in a flatwise orientation by placing them on two elastic supports and hitting them with a hammer (Figure 2). Response vibration signals along the longitudinal direction were collected with a t.bonne MM-1 Thomann microphone (Thomman $\mathrm{GmbH}$, Burgebrach, Germany) and transduced to an electrical signal recorded with a Picoscope ${ }^{\circledR}$ 4424 oscilloscope with $80 \mathrm{MS} / \mathrm{s}$ (Pico Technology, Cambridgeshire, UK). The fundamental resonance frequency $f_{1}$ of each plank was obtained by means of spectral analysis. Using this frequency and the density of each plank $\left(\rho_{\mathrm{p}}\right)$, the dynamic elastic modulus $\left(\mathrm{MoE}_{\mathrm{dyn}, \mathrm{p}}\right)$ can be estimated as follows:

$$
\begin{gathered}
\mathrm{v}=2 \mathrm{Lf}_{1} \\
\mathrm{MoE}_{\mathrm{dyn}, \mathrm{p}}^{*}=\rho_{\mathrm{p}} \mathrm{v}^{2}
\end{gathered}
$$


where $\mathrm{L}$ is the plank length, and $\mathrm{v}$ is the propagation velocity of the stationary elastic wave. Furthermore, a correction of the dynamic elastic modulus $\left(\mathrm{MoE}_{\mathrm{dyn}, \mathrm{p}, 12}\right)$ from the real $\mathrm{MC}_{\mathrm{p}}$ measured with a digital moisture meter to the $\mathrm{MC}=12 \%$ was carried out according to the standard [25] as

$$
\mathrm{MoE}_{\mathrm{dyn}, \mathrm{p}}=\mathrm{MoE}_{\mathrm{dyn}, \mathrm{p}}^{*} \cdot\left(1+0.01\left(\mathrm{MC}_{\mathrm{p}}-\mathrm{MC}_{12 \%}\right)\right)
$$
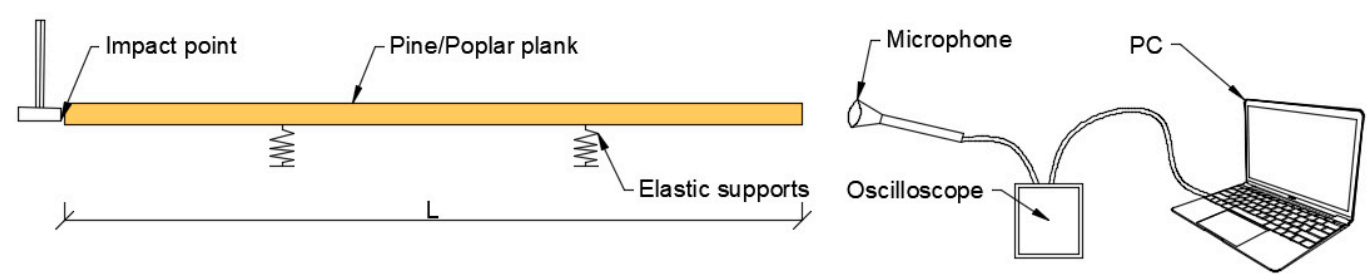

Figure 2. ART layout for planks. L = Plank length.

Figure 3 depicts the dynamic modulus of elasticity of all the planks. Results for poplar and pine follow normal distributions, with smaller values of the dynamic elastic modulus and a more reduced deviation values for the case of poplar timber compared with pine.

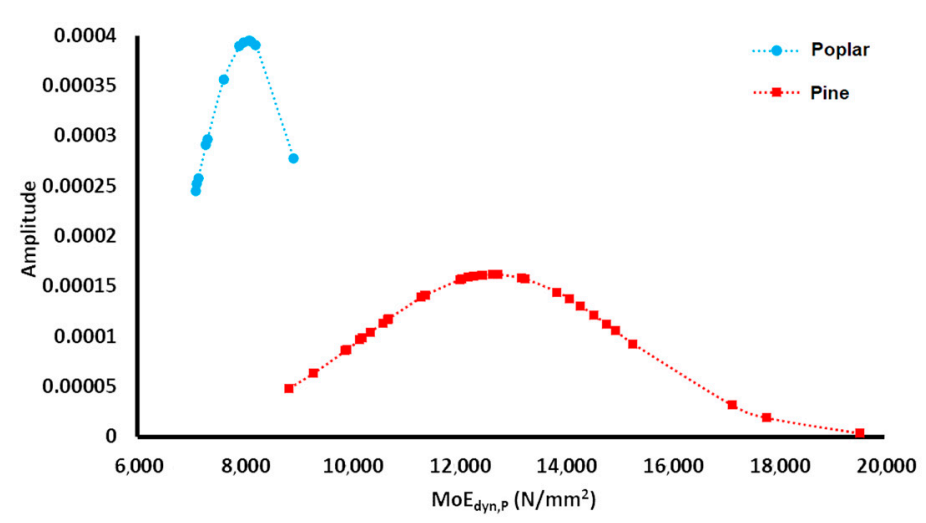

Figure 3. Normal distribution of the dynamic modulus of elasticity of the planks.

\subsection{Planks Strength Grading}

By using the $\mathrm{MoE}_{\mathrm{dyn}, \mathrm{p}}$, all the planks were graded according to Table 1 in Section 5.1.4.1 from reference [26]. That standard also associates the T strength class of the planks, which comply with the minimum values of $C$ strength class for sawn structural timber according to standard [27]. Figure 4 shows the distribution of planks for each particular $\mathrm{T}$ and $\mathrm{C}$ class. Within each $\mathrm{T}$ strength class, the planks were considered structurally equivalent and were randomly selected for glulam timber manufacturing.

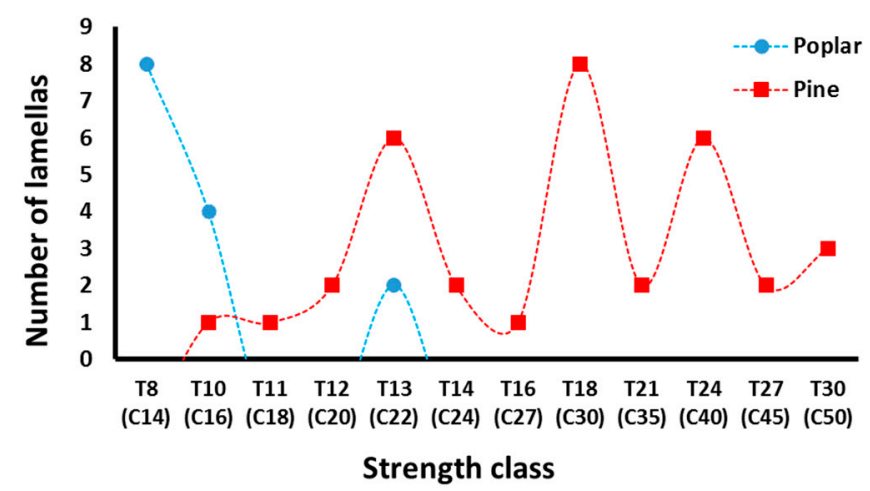

Figure 4. Distribution of planks according with the T and C strength class. 


\subsection{Glulam Timber Samples}

Three different types of 4-layers laminated timber were designed and compared; single-species poplar (PPo), single-species pine ( $\mathrm{PPi}$ ) and mixed poplar/pine (MPoPi) as shown in Figure 5. Two samples were manufactured for each type. Based on the $\mathrm{T}$ strength class of the planks and the recommendations for homogeneous timber given by Table 2 in Section 5.1.4.3 from reference [26], different layouts were set up for the case of pine or poplar single-species layouts used as control specimens. Figure 5 indicates also the GL strength class theoretically assigned by the mentioned standard (named in this paper as "design class"), except for the case of poplar/pine mixed timber because the standard does not consider multispecies layouts, and for the PPo1 sample due to the very low out-standard strength class of the poplar planks (T8). It should be also noticed that the pine planks of the single-species pine control sample PPi2 and mixed sample MPoPi1 have the same design class-T24. Thus, its mutual comparison can be used to evaluate the influence of the substitution of inner pine planks by poplar ones.

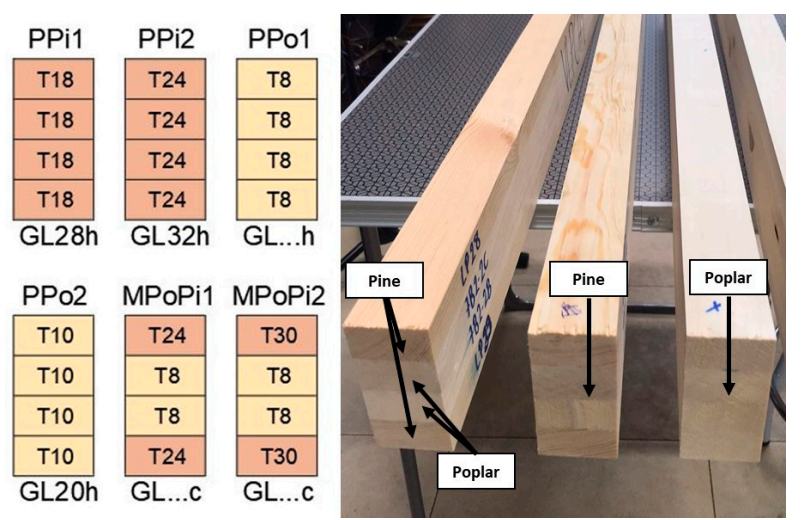

Figure 5. Timber layers design according with planks grading and strength class GL proposed by the standard [26]. PPi: single-species pine. PPo: single-species poplar. MPoPi: mixed poplar/pine. GLXc: design grading for combined. GLXh: design grading for homogeneous.

The planks were glued to each other by using the polyurethane resin PUR-20 from Bakar ${ }^{\circledR}$ (Bakar, Vizcaya, Spain) with an amount of adhesive of $350 \mathrm{~g} / \mathrm{m}^{2}$, applying a constant pressure of $6 \times 10^{-7} \mathrm{MPa}$ during $4 \mathrm{~h}$ without using any finger joints. The elaboration process was carried out following the requirements of the standard [26]-(Annex I). During the elaboration process the temperature and humidity of the room (HR) was of $20{ }^{\circ} \mathrm{C}$ and $40 \%$. As indicated by the standard, the time between mechanization and gluing of the planks was lower than $24 \mathrm{~h}$. The resulting dimensions of the samples were $\mathrm{b}=40 \mathrm{~mm}, \mathrm{~h}=80 \mathrm{~mm}$, and $\mathrm{L}=1230 \mathrm{~mm}$.

\subsection{Dynamic Modulus of Elasticity of the Glulam Timber}

Each particular sample was subjected to a longitudinal ART [20,21] as described in Section 2.3 and shown in Figure 2, thus obtaining the longitudinal dynamic modulus of elasticity $\left(\mathrm{MoE}_{\mathrm{dyn}, \mathrm{gt}}\right)$, including the $\mathrm{MC}=12 \%$ correction for each sample.

\subsection{Semi-Analytical Modulus of Elasticity}

Since the samples are formed by planks with similar elastic properties, the Parallel Axes theorem [28] can be used to semi-analytically obtain a combined modulus of elasticity, $\mathrm{MoE}_{\mathrm{c}}$. It was calculated by using the experimental dynamic modulus of elasticity $\left(\mathrm{MoE}_{\mathrm{dyn}, \mathrm{p}}\right)$ for each individual planks, as

$$
\mathrm{MoE}_{\mathrm{c}}=\sum_{\mathrm{l}=1}^{\mathrm{N}} \frac{\mathrm{MoE}_{\text {dyn }, \mathrm{p}} \cdot \mathrm{I}_{\mathrm{p}}+\mathrm{A}_{\mathrm{p}} \cdot \mathrm{MoE}_{\text {dyn }, \mathrm{p}} \cdot \mathrm{y}_{\mathrm{p}}^{2}}{\mathrm{I}_{\mathrm{c}}}
$$


where Ip is the second moment of inertia respect to sample axis, Ap is the cross-section of the sample, $y_{p}$ is the distance from the combined neutral axis to the neutral axis for each particular plank $p$, and $I_{C}$ is the combined second moment of inertia.

\subsection{Bending Test}

Following the standard [24], a monotonic four-point bending test was performed for each particular sample (see Figure 6). Due to the plank sizes and in order to avoid torsion effects caused by a small base of the samples, a $14 \mathrm{~h}$ ratio was set, scaling the standard arrangement. Displacement control ratio was set at $4 \mathrm{~mm} / \mathrm{min}$, in order to fulfill the requirements of the aforementioned standard. A 100 kN-capacity testing machine (Equipos de ensayo Controls S.A., Toledo, Spain) was used. Two strain gauges were glued at the mid-spam section of the sample on the bottom and top faces, in order to measure the maximum tensile and compression strains, respectively. The span between supports was set as $1130 \mathrm{~mm}$. The maximum stress $\sigma_{\max }$ was calculated as

$$
\sigma_{\max }=\frac{M_{\max }}{W}
$$

where $\mathrm{M}_{\max }=\mathrm{F}_{\max } \mathrm{a} / 2$ is the maximum bending moment and $\mathrm{W}$ is the section modulus (see Figure 6 for the meaning of a). Similarly, the static modulus of elasticity $\mathrm{MoE}_{\mathrm{st}}$ was calculated by using the stress-tensile strain curve, as the slope in the linear range between $20-40 \%$ of the maximum stress. Moreover, the global modulus of elasticity $\mathrm{MoE}_{\mathrm{st}, \mathrm{g}}$ was also obtained according to Section 10.3 from reference [24], as

$$
\mathrm{MoE}_{\mathrm{st}, \mathrm{g}}=\frac{3 \mathrm{aL}^{2}-3 \mathrm{a}^{3}}{2 \mathrm{bh}^{3\left(2 \frac{\delta 40-\delta 20}{\mathrm{~L} 40-\mathrm{L} 20}-\frac{6 \mathrm{a}}{5 \mathrm{Gbh}}\right)}}
$$

by using the load-displacement $(\mathrm{L}-\delta)$ curve, in the same load range as $\mathrm{MoE}_{\mathrm{st}}(20-40 \%$ of the maximum load). The displacement was measured by means of a LVDT placed as shown in Figure 7.
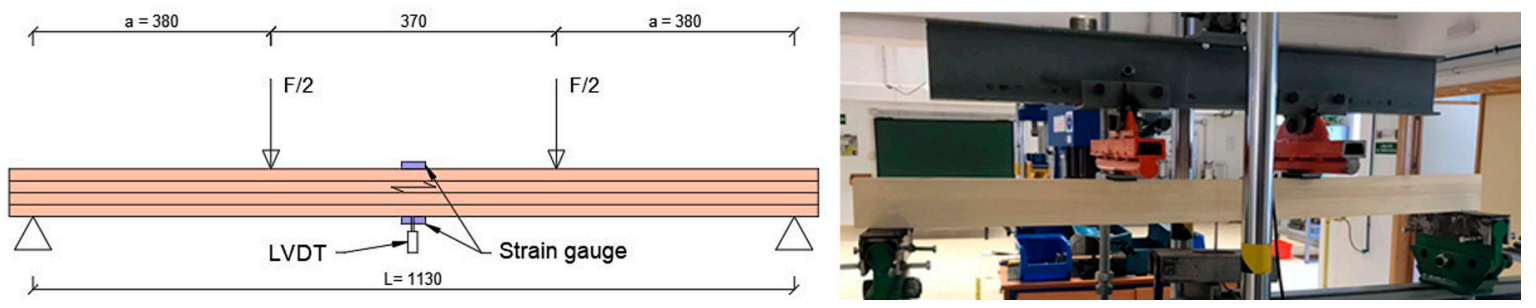

Figure 6. Left: Four-point bending test arrangement. Right: single-species poplar sample during the bending test. Distances in $\mathrm{mm}$.
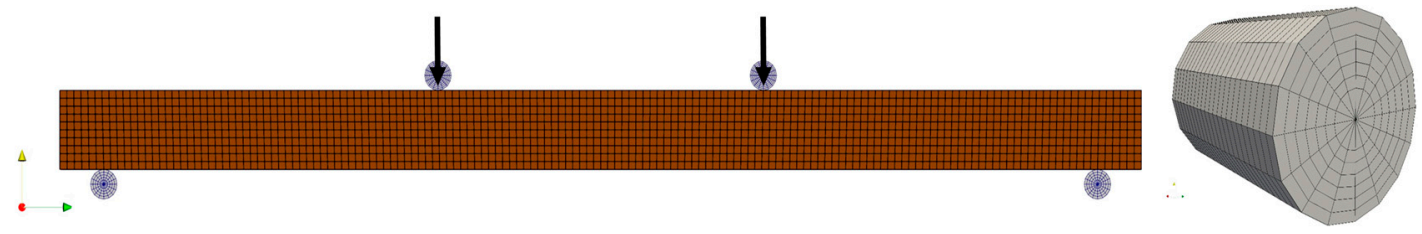

Figure 7. Left: 3D-FEM model for a four-point bending test set-up. Right: 3D-Mesh of load cells/supports.

\subsection{Strength Grading of Glulam Timber Samples}

All the mechanical properties were considered initially for the strength grading but the density and maximum stress in bending were not the critical properties for strength grading. Thus, all the samples were graded taking into account the critical property, the modulus of elasticity as follows: (1) Using the dynamic modulus $\mathrm{MoE}_{\mathrm{dyn}, \mathrm{gt}}$; (2) Using the semi-analytical combined elastic modulus $\mathrm{MoE}_{\mathrm{dyn}, \mathrm{c}} ;$ (3) Using the static modulus $\mathrm{MoE}_{\mathrm{st}}$. 


\subsection{Numerical Modelling}

A three-dimensional finite element model (3D-FEM) was developed into the open source finite element code Salome Meca ${ }^{\circledR}$ (Version 2019, Code Aster, France) [29] to evaluate the behavior of the manufactured glulam timber subjected to four-point bending test. The samples were modeled as elasto-plastic solids and nonlinear analyses were performed using a linear elasto-plastic constitutive model with hardening. The constitutive model received as input parameters the elastic modulus, shear modulus and Poisson ratio for the linear elastic part, and the yield stresses for the plastic part with hardening. The 3D-FEM model consists of one piece with a rectangular cross-section and four simply supported solid rollers (see Figure 7). Bottom rollers represent the supports and top ones the points of application of the loads in the testing machine. In order to get accurate results with reasonable computational cost, an analysis of convergence of results dependent of element size was carried out. An optimum size of $8 \mathrm{~mm}$ was achieved and the sample was meshed into 9240 eight-node brick elements having a total number of 11,935 nodes. Each roller was meshed into 1648 six-node wedge elements with a total number of 1109 of nodes, allowing a proper adaptation to the cylindrical shape. The right subfigure in Figure 7 shows the defined mesh for the supports and load cells in detail. The average radial size for each element was $2.75 \mathrm{~mm}$ and an outermost size of $5.85 \mathrm{~mm}$ was adopted, resulting in a total roller diameter of $30 \mathrm{~mm}$. Due to the set-up of the experimental part, four-point bending test, the material definition of the 3D-FEM model was considered to be isotropic. In this case, the specimen is working mainly in the longitudinal direction without any transverse constraints and the mechanical properties in the longitudinal direction are the most relevant for this analysis. The isotropic model also implies an intermediate-low computational cost without important influence in the results. Rollers for the experimental test were made of steel so, in consequence, the elastic modulus of $210 \mathrm{GPa}$ and the Poisson's ratio of 0.3 were considered.

In coherence with the experimental test, bottom rollers were restrained to move in any direction and the top rollers (points of load application) were constrained to remain horizontal, while being able to rotate and moving vertically during the simulation. Previous authors [23] use similar numerical setups without modelling contact interactions from supports and loads cells. Further, a contact restriction between roller and the laminated specimen surface was prescribed. Definition of contact requires the description contact candidates which comprise the slave and master surfaces [30]. The contact formulation, applied to the simulation, are normal and frictional penalties [31] due to their ability to soften the nonlinearities induced by contact. The mechanical stiffness of penalty springs was calibrated to $1 \times 10^{9} \mathrm{kN} / \mathrm{m}$ according to the guidelines given in [32], while the friction coefficient was set to 0.3 , which is a common value for the friction for steel surfaces. In order to simulate the whole experimental process and to improve the convergence of the contacts, the load increases linearly and is applied in the center of gravity of each top roller.

The set of nonlinear equations from the finite element model was solved with a direct full Newton nonlinear solver. The solution provides the displacements, elastic/plastic stresses and strains at each increment. A set of nodes located at the bottom face of the mid-span, in the same positions as LVDTs, was used to obtain the deflection during the simulation.

Moreover, in order to obtain the mechanical properties for the FEM model, a calibration process was carried out. It consisted of running the analysis using a starting value of elastic modulus, equal to the one determined through the experimental part $\left(\mathrm{MoE}_{\mathrm{st}}\right)$, and then the elastic and plastic parameters as the yielding stress $\left(\sigma_{\mathrm{y}}\right)$ were adjusted to fit the experimental patterns. In order to compute a reasonable shear modulus (G), $\mathrm{MoE}_{\mathrm{st}}$ is enforced to be equal to $\mathrm{MoE}_{\mathrm{st}, \mathrm{g}}$ in Equation (6). The rest of known parameters from Equation (6) represent: $\mathrm{L}$, the span of the sample; $\mathrm{a}$, the distance between the supports and its nearest point of load application; $b$, the base of the sample; $h$, the height of the sample; L20 and L40, the load at $20 \%$ and $40 \%$ of the maximum load, respectively; and $\delta 20$ and $\delta 40$, the corresponding displacement registered with de LVDT at that load values. Thus, the only unknown to be solved is the value of the shear modulus G. The Poisson's ratio $(v)$ was set as 0.37 by means of tests performed in [33]. Two calibration processes were carried out by considering $\mathrm{G}$ or not, thus obtaining 
the calibrated modulus of elasticity $\mathrm{MoE}_{\mathrm{FEM}, \mathrm{G}}$ and $\mathrm{MoE}_{\mathrm{FEM}}$, respectively. In both cases, the calibration procedure was considered to be finished when the difference between numerical and experimental stiffness in the elastic regime was lower than $5 \%$. Increments of applied load, $\Delta \mathrm{L}$, and corresponding displacements, $\Delta \delta$, were used to compute the stiffness $\mathrm{K}$ applying the following relation:

$$
\mathrm{K}=\frac{\Delta \mathrm{L}}{\Delta \delta}
$$

Stiffness of the samples was computed between 15 and $35 \%$ of the elastic range, based on the force-displacement relationship, for both the numerical and experimental part.

\section{Results}

Figure 8 shows the stress-strain curves for all the samples by using the tensile strain gauge. The samples are clearly grouped in three groups, following the order MPoPi $>$ PPi $>$ PPo. The single-species pine PPi2 sample and mixed MPoPi1 sample had very similar behavior, as Figure 8 shows. This relationship can be also observed in Figure 9, which compares the different static modulus of elasticity and strength class using the $\mathrm{MoE}_{\mathrm{st}}$. Figure 10 plots the load-displacement relations and their corresponding yield limits, comparing experimental and numerical results. An excellent agreement can be observed for all the tested samples. Table 1 summarizes the results obtained for each sample, i.e., static, dynamic, semi-analytical, and numerical modulus as well as the maximum stress. The four parameters also follow the order previously mentioned, i.e., $\mathrm{MPoPi}>\mathrm{PPi}>\mathrm{PPo}$. Figure 11 represents the relationship between the static and dynamic moduli, in which it can be observed that the higher variations were reached by the mixed samples. Table 2 presents the strength grading results with the different elastic moduli.

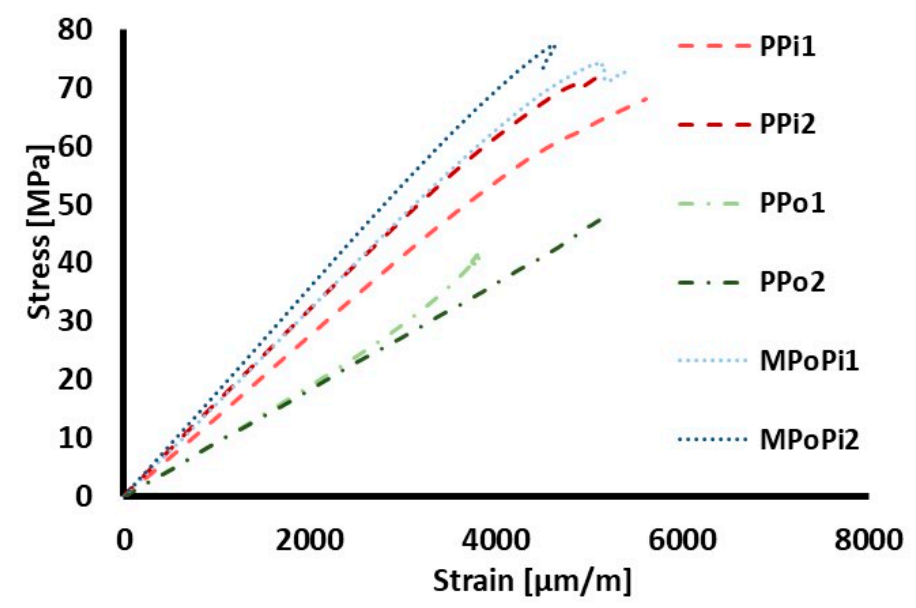

Figure 8. Stress versus strain for the tensile strain gauge (bottom face) for all the samples.
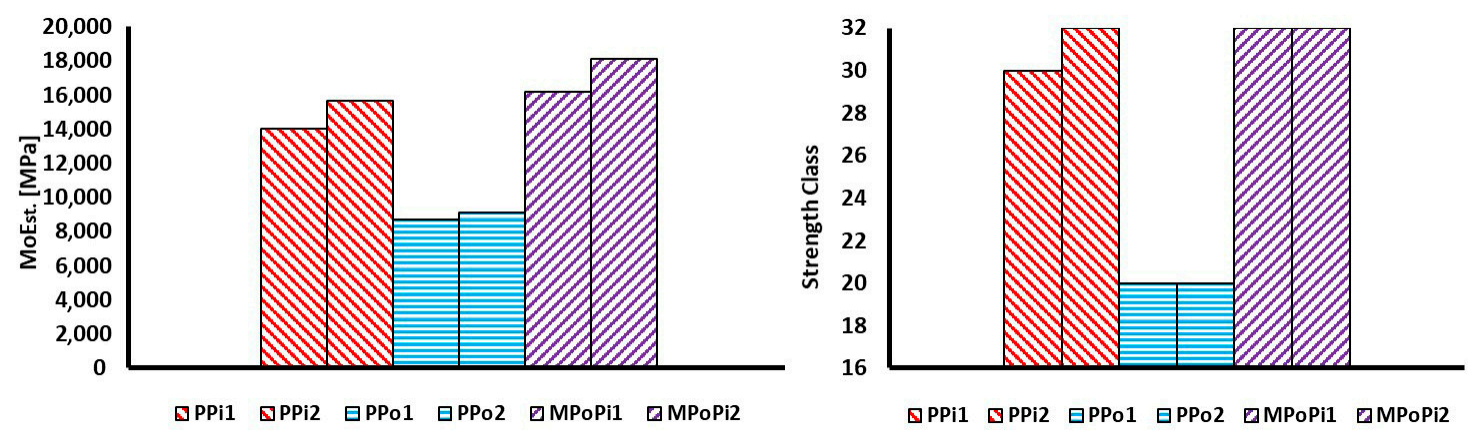

Figure 9. General results for the tested samples. Left: Static modulus of elasticity $\left(\mathrm{MoE}_{\mathrm{st}}\right)$. Right: Strength grading of the samples with $\mathrm{MoE}_{\mathrm{st}}$. 

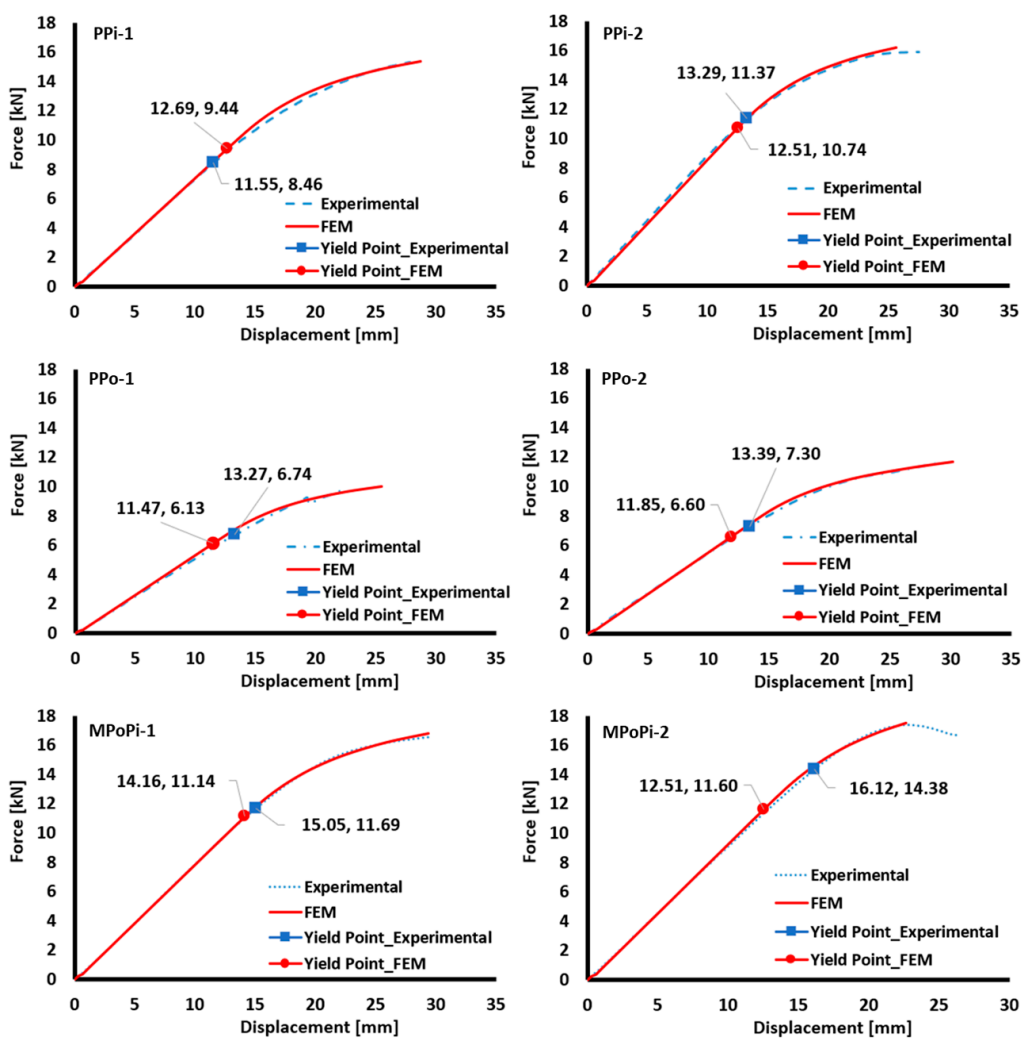

Figure 10. Numerical and experimental load-displacement plots and their corresponding yield limits.

Table 1. Main mechanical properties of the tested samples. $\mathrm{MoE}_{\mathrm{st}}$ : static modulus of elasticity. $\mathrm{MoE}_{\mathrm{FEM}, \mathrm{G}}$ : numerical modulus of elasticity using $\mathrm{G}$. MoE $\mathrm{E}_{\mathrm{dyn}, \mathrm{gt}}$ : dynamic modulus of elasticity. $\mathrm{MoE}_{\mathrm{c}}$ : semi-anaytical modulus of elasticity. $\sigma_{\max }$ : Maximum stress. PPi: Single-species pine. PPo: Single-species poplar. MPoPi: mixed poplar/pine. T $T^{\mathrm{o}}$ Outer planks. $\mathrm{T}^{\mathrm{i}}$ : Inner planks.

\begin{tabular}{|c|c|c|c|c|c|c|}
\hline Sample Name & Planks SC & $\mathrm{MoE}_{\text {st }}(\mathrm{MPa})$ & $\mathrm{MoE}_{\mathrm{FEM}, \mathrm{G}}(\mathrm{MPa})$ & $\mathrm{MoE}_{\mathrm{dyn}, \mathrm{gt}}(\mathrm{MPa})$ & $\mathrm{MoE}_{\mathrm{c}}(\mathrm{MPa})$ & $\sigma_{\max }(\mathrm{MPa})$ \\
\hline PPi1 & T18 & 14,003 & 13,030 & 12,420 & 12,463 & 62.3 \\
\hline PPi2 & $\mathrm{T} 24$ & 15,644 & 15,544 & 14,888 & 14,604 & 65.8 \\
\hline PPo1 & $\mathrm{T} 8$ & 8703 & 8603 & 7689 & 7554 & 39.7 \\
\hline PPo2 & $\mathrm{T} 10$ & 9098 & 8908 & 8699 & 8462 & 49.8 \\
\hline MPoPi1 & $\mathrm{T}^{\mathrm{o}} 24, \mathrm{~T}^{\mathrm{i}} 8$ & 16,162 & 15,021 & 11,612 & 13,328 & 67.4 \\
\hline MPoPi2 & $\mathrm{T}^{\mathrm{o}} 30, \mathrm{~T}^{\mathrm{i}} 8$ & 18,116 & 17,444 & 12,557 & 16,332 & 70.6 \\
\hline
\end{tabular}

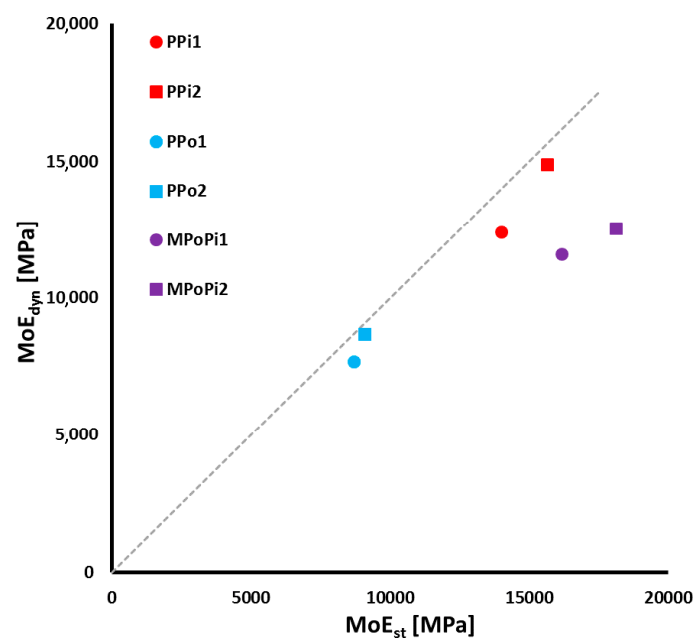

Figure 11. Comparison between modulus of elasticity for the tested samples. $\mathrm{MoE}_{\mathrm{dyn}, \mathrm{gt}}$ : dynamic modulus of elasticity. $\mathrm{MoE}_{\mathrm{st}}$ : static modulus of elasticity. Gray dotted line: $\mathrm{y}=\mathrm{x}$. 
Table 2. Strength grading for the tested samples according to the different modulus of elasticity. $\mathrm{MoE}_{\mathrm{st}}$ : static modulus of elasticity. $\mathrm{MoE}_{\mathrm{dyn}, \mathrm{gt}}$ : dynamic modulus of elasticity. $\mathrm{MoE}_{\mathrm{c}}$ : semi-anaytical modulus of elasticity. PPi: single-species pine. PPo: single-species poplar. MPoPi: mixed poplar/pine. $\mathrm{T}^{\mathrm{o}}$ : Outer planks. $\mathrm{T}^{\mathrm{i}}$ : Inner planks.

\begin{tabular}{cccccc}
\hline Sample Name & SC Planks & SC Design & SC $\left(\mathbf{M o E}_{\mathbf{s t}}\right)$ & SC $\left(\mathbf{M o E}_{\mathbf{d y n}, \mathbf{g t}}\right)$ & $\mathbf{S C}\left(\mathbf{M o E}_{\mathbf{c}}\right)$ \\
\hline PPi1 & T18 & GL28h & GL30h & GL26h & GL26h \\
PPi2 & T24 & GL32h & GL32h & GL32h & GL32h \\
PPo1 & T8 & - & GL20h & - & - \\
PPo2 & T10 & GL20h & GL20h & GL20h & GL20h \\
MPoPi1 & T $^{\mathrm{o}} 24, \mathrm{~T}^{\mathrm{i}} 8$ & - & GL32c & GL24c & GL30c \\
MPoPi2 & $\mathrm{T}^{\mathrm{o}} 30, \mathrm{~T}^{\mathrm{i}} 8$ & - & GL32c & GL28c & GL32c \\
\hline
\end{tabular}

\section{Discussion}

It can be observed that, when the design strength class is available, a good agreement with the experimental and design strength is achieved. Moreover, as expected, higher mechanical properties are obtained for single species pine and mixed poplar/pine samples, compared with those for single-species poplar samples, due to the lower grading of poplar timber compared with pine. However, similar values of $\mathrm{MoE}_{\text {st }}$ are obtained for single-species pine sample PPi2 and mixed sample MPoPi1, the difference being no bigger than 3\%, since they both used T24 pine planks in the outer layers. This demonstrates that the inner layers do not contribute significantly to the sample elastic modulus, allowing the use of low-grade species such as poplar for these inner planks. As mentioned by Moody [9], when mixing species, the outer layers of the samples provide the main stiffness contribution to the total sample. In particular, it is observed that by applying the Parallel Axes theorem (Equation (4)) and using the dynamic elastic modulus obtained for each plank, it is possible to obtain the contribution of each particular plank to the total modulus. As an example, Table 3 presents the results for the single-species pine PPi2 and mixed poplar/pine MPoPi1 samples, with their corresponding planks strength classes and dynamic moduli of elasticity. The results clearly demonstrate that for both planks the outer planks contribute with $87 \%$ and $95 \%$ of the total stiffness for the PPi2 and MPoPi1 planks, respectively, just leaving only $13 \%$ and $7 \%$ of modulus contribution for the inner planks.

Table 3. Parallel Axes theorem results for the single-species pine PPi2 and mixed poplar/pine MPoPi1 samples. $\mathrm{T}^{\mathrm{o}}$ : Outer planks. $\mathrm{T}^{\mathrm{i}}$ : Inner planks. $\mathrm{MoE}_{\mathrm{dyn}, \mathrm{p}}$ : dynamic modulus of elasticity of each plank. $\mathrm{MoE}_{\mathrm{c}}$ : semi-analytical dynamic modulus of elasticity.

\begin{tabular}{cccc}
\hline Sample & SC Planks & MoE $_{\mathbf{d y n}, \mathbf{p}}(\mathbf{M P a})$ & Contribution to the Total $\mathbf{M o E}_{\mathbf{c}}(\mathbf{\%})$ \\
\hline \multirow{4}{*}{ PPi2 } & $\mathrm{T}^{\mathrm{o}} 24$ & 14,708 & 44.1 \\
& $\mathrm{~T}^{\mathrm{i}} 24$ & 14,932 & 6.4 \\
& $\mathrm{~T}^{\mathrm{i}} 24$ & 14,693 & 6.3 \\
& $\mathrm{~T}^{\mathrm{o}} 24$ & 14,441 & 43.3 \\
\hline \multirow{3}{*}{ MPoPi1 } & $\mathrm{T}^{\mathrm{o}} 24$ & 14,234 & 46.7 \\
& $\mathrm{~T}^{\mathrm{i}} 8$ & 7982 & 3.7 \\
& $\mathrm{~T}^{\mathrm{i}} 8$ & 7611 & 3.6 \\
& $\mathrm{~T}^{\mathrm{o}} 24$ & 14,002 & 46.0 \\
\hline
\end{tabular}

Table 4 shows the variations of the numerical, dynamical and semi-analytical moduli respect to the static modulus $\mathrm{MoE}_{\text {st }}$. It can be observed that the variations between experimental and numerical results are very small, always below $8 \%$ for all the types of samples. In many cases, those differences are even less than $2 \%$, demonstrating the effectiveness of the numerical modelling and calibration procedure using the shear modulus. More in detail, as shown in Figure 10, an excellent performance is achieved in the elastic range. Meanwhile, when plastification occurs, both experimental and numerical curves start to diverge, mainly due to the complex phenomena at this load stage (cracking, debonding, 
etc.). Moreover, the limit between elastic and plastic ranges is clearly separated by the definition of the yielding points for both approaches, as shown on the Figure 10. A big similarity is observed for this transition for both experimental and numerical methodologies.

Table 4. Variation in \% of the elastic moduli respect to the static modulus $\mathrm{MoE}_{\mathrm{st}}$. Comparison of the numerical and experimental moduli of elasticity. $\mathrm{MoE}_{\mathrm{st}}$ : static modulus of elasticity. MoE $\mathrm{FEM}_{\mathrm{G}}$ : calibrated modulus of elasticity using G. $\mathrm{MoE}_{\mathrm{dyn}, \mathrm{gt}}$ : dynamic modulus of elasticity. MoE $\mathrm{dyn}, \mathrm{c}_{\mathrm{c}}$ : semi-analytical modulus of elasticity. PPo: Single-species poplar. MPoPi: mixed poplar/pine.

\begin{tabular}{cccc}
\hline Sample Name & Variation of $\mathbf{M o E}_{\mathrm{FEM}, \mathbf{G}} \mathbf{( \% )}$ & Variation of $\mathbf{M o E}_{\mathbf{d y n}, \mathbf{g t}} \mathbf{( \% )}$ & Variation of $\mathbf{M o E}_{\mathbf{d y n}, \mathbf{c}}(\mathbf{\%})$ \\
\hline PPi1 & 7.5 & 12.7 & 12.4 \\
PPi2 & 0.6 & 5.1 & 6.0 \\
PPo1 & 1.2 & 13.2 & 15.2 \\
PPo2 & 2.1 & 4.6 & 7.5 \\
MPoPi1 & 7.6 & 39.2 & 21.3 \\
MPoPi2 & 3.8 & 44.3 & 10.9 \\
\hline
\end{tabular}

When comparing the dynamic modulus and the semi-analytical moduli with the static modulus $\mathrm{MoE}_{\mathrm{st}}$, the variations become lower than $15 \%$ for the case of pine and poplar single-species samples, demonstrating the effectiveness of these non-destructive methodologies. It can be observed how the results (elastic modulus and strength grading) are very similar to each other with both non-destructive methods. However, big variations are observed for the case of mixed samples, around $40 \%$ for the case of the dynamic modulus and $20 \%$ for the semi-analytical one. These high variations can be associated to the heterogeneity of the cross-section and the high variation of the strength class of the planks, T8 for the inner layers and T24 and T30 for the outer layers, respectively. Considering this fact, both non-destructive methods (especially the ART carried out on the whole laminated sample) are unable to provide reliable strength grading. These results are confirmed in Figure 11, in which the points corresponding to the mixed samples significantly move away from the $\mathrm{y}=\mathrm{x}$ straight line. However, the points corresponding the single-species samples fall almost on this straight line.

It should be emphasized that the good agreement between numerical and experimental moduli is mainly due to the calibration process using the shear modulus $(G)$. In order to discuss this issue, the influence of the shear modulus $(G)$ is analyzed in Table 5, in which the experimental global modulus $\mathrm{MoE}_{\mathrm{st}, \mathrm{g}}$ and the numerical modulus $\mathrm{MoE}_{\mathrm{FEM}}$, and their variations respect to the static modulus $\mathrm{MoE}_{\mathrm{st}}$, are shown. The global modulus $\mathrm{MoE}_{\mathrm{st}, \mathrm{g}}$ is obtained experimentally, and it does not include the shear effect. Similarly, MoE FEM is calculated without including $\mathrm{G}$ in the model. It is clearly observed that in both cases, very high variations are obtained (between 9-50\%). It demonstrates the need to include $\mathrm{G}$ in both experimental global modulus and numerical modelling procedures. As a reference, Table 6 shows the value of the experimental and the calibrated shear moduli. A big similarity is obtained between them for all the tested samples.

Table 5. Comparison of experimental and numerical moduli of elasticity without considering the shear modulus and their variation in \% respect to the static modulus $\mathrm{MoE}_{\mathrm{st}}$. MoEst: static modulus of elasticity. $\mathrm{MoE}_{\mathrm{st}, \mathrm{g}}$ : global static modulus of elasticity. $\mathrm{MoE}_{\mathrm{FEM}}$ : calibrated modulus of elasticity without using G.

\begin{tabular}{ccccc}
\hline Sample Name & MoE $_{\text {st, }} \mathbf{( M P a )}$ & Variation of $\mathbf{M o E}_{\mathbf{s t}, \mathbf{g}}(\mathbf{\%})$ & MoE $_{\mathrm{FEM}}(\mathbf{M P a})$ & Variation MoE \\
\hline FEM & $(\%)$ \\
PPi1 & 11,474 & 22.0 & 11,000 & 27.3 \\
PPo1 & 12,830 & 21.9 & 12,544 & 24.7 \\
PPo2 & 7976 & 9.1 & 7503 & 16.0 \\
MPoPi1 & 8322 & 9.3 & 8008 & 13.6 \\
MPoPi2 & 11,955 & 35.2 & 11,260 & 43.5 \\
\hline
\end{tabular}


Table 6. Comparison of the shear moduli of elasticity. $\mathrm{G}_{\mathrm{ex}}$ : experimental shear modulus. $\mathrm{G}_{\mathrm{FEM}}$ : calibrated shear modulus used for numerical simulation.

\begin{tabular}{ccc}
\hline Sample Name & $\mathbf{G}_{\mathbf{e x}} \mathbf{( M P a )}$ & $\mathbf{G}_{\text {FEM }} \mathbf{( M P a )}$ \\
\hline PPi1 & 300 & 300 \\
PPi2 & 361 & 317 \\
PPo1 & 451 & 401 \\
PPo2 & 460 & 410 \\
MPoPi1 & 217 & 229 \\
MPoPi2 & 274 & 284 \\
\hline
\end{tabular}

Finally, Table 7 depicts the stiffness obtained from the numerical simulations and experimental data from Figure 10. As mentioned above, the elastic range is very similar for both phases, supported by a low value of error between numerical and experimental stiffness, which is below $4 \%$. It is clear that the single-species poplar samples show the lowest stiffness as confirmed by the results, while the mixed pine poplar sample MPoPi2 show the highest one, due to the existence of the T30 plank's strength class at the outer layers. The single-species pine samples show a relatively small reduction in stiffness compared with the MPoPi-2 specimen, which demonstrates that the extreme fibers have the highest contribution to the general strength of the sample. In particular, by comparing PPi2 and MPoPi1 samples, which are composed by the same strength class of outer planks, T24, it is clear that the insertion of poplar planks at the inner part produces a very small reduction in stiffness. Similarly, the results from Table 7 also show that the shear modulus does not play an important role in the computation of stiffness (K), keeping a variation below 3.5\% with and without using G.

Table 7. Experimental and numerical stiffness used for the calibration of the FEM model. $\mathrm{K}_{\mathrm{ex}}$ : experimental stiffness. $\mathrm{K}_{\mathrm{FEM}, \mathrm{G}}$ : calibrated numerical stiffness using $\mathrm{G}$. $\mathrm{K}_{\mathrm{FEM}}$ : calibrated numerical stiffness without using G. Variation in \% computed respect to $K_{e x}$.

\begin{tabular}{|c|c|c|c|c|c|}
\hline Sample Name & $\mathrm{K}_{\mathrm{ex}}(\mathrm{N} / \mathrm{mm})$ & $\mathrm{K}_{\mathrm{FEM}, \mathrm{G}}(\mathrm{N} / \mathrm{mm})$ & Variation of $\mathrm{K}_{\mathrm{FEM}, \mathrm{G}}(\%)$ & $\mathrm{K}_{\mathrm{FEM}}(\mathrm{N} / \mathrm{mm})$ & Variation of $\mathrm{K}_{\mathrm{FEM}}(\%)$ \\
\hline PPi1 & 760 & 761 & 0.1 & 765 & 0.5 \\
\hline PPi2 & 850 & 880 & 3.4 & 881 & 3.5 \\
\hline PPo1 & 529 & 548 & 3.5 & 552 & 1.3 \\
\hline РPo2 & 551 & 565 & 2.5 & 564 & 2.2 \\
\hline MPoPi1 & 792 & 805 & 1.6 & 783 & 1.2 \\
\hline MPoPi2 & 915 & 949 & 3.6 & 935 & 2.2 \\
\hline
\end{tabular}

\section{Conclusions}

An experimental and numerical comparison of the mechanical behavior and strength grading between single-species pine and poplar and mixed poplar/pine laminated timber has been carried out. The main conclusions of the paper are as follows:

- Higher mechanical properties are obtained for single-species pine and mixed poplar/pine laminated timber, compared with single-species poplar specimens, due to the lower grading of poplar timber compared with pine.

- The inner planks do not contribute significantly to the whole sample elastic modulus, allowing the use of low-graded species such as poplar for the inner layers of the sample.

- After calibration and using the shear modulus in the formulation, a good agreement is obtained between numerical and experimental results. The use of the shear modulus in the formulation must be considered in order to obtain very low variations with the experimental results. Similarly, the experimental global modulus—without including the shear effect—does not provide reliable results with very high variations.

- The dynamic modulus and the semi-analytical elastic modulus obtained from the ART non-destructive grading of the whole sample or particular planks, respectively, is in good 
agreement with the static modulus and consequent strength grading for the case of single-species samples, with relatively low variations.

- Non-destructive testing grading based on ART provide a very low grading yield for the case of mixed samples, with very high variations. Thus, this methodology should be reformulated and adapted in the future in order to get more reliable grading results.

- The insertion of low-grade poplar planks at the inner layers produces a very small reduction in the stiffness compared with the single-species pine type.

- The shear modulus does not play an important role in the computation of stiffness (K), with very low variations between using and not using $\mathrm{G}$.

- It should be emphasized that due to the low number of samples used for each layout, the results of this work should be considered only in qualitative and not in quantitative terms. In a future work, the elaboration of the glulam timber using the technology of the finger joints as performed industrially will be considered.

Author Contributions: Conceptualization, A.G. and C.T.; methodology, A.G., C.T. and F.J.R.; software and validation, C.T. and R.B.; investigation, A.G., C.T., F.J.R. and R.B.; resources, A.G. and R.B.; data, C.T. and F.J.R.; writing-original draft preparation, A.G.; writing-review and editing, all authors; All authors have read and agreed to the published version of the manuscript.

Funding: This work has been possible due to the financial support of the COMPOP_Timber project "Desarrollo de productos de ingeniería elaborados a base de tablones y chapas de chopo con inserciones de material compuesto para su uso en construcción", BIA2017-82650-R.

Acknowledgments: The authors thank to Madera PINOSORIA for its support with pine timber and sawing process.

Conflicts of Interest: The authors declare no conflict of interest.

\section{Abbreviations}

Greek symbols:

$\sigma_{\max } \quad$ Maximum normal stress in bending

$\delta_{20}, \delta_{40} \quad$ Beam deflection at $20 \%$ and $40 \%$ of the maximum load

$\Delta \mathrm{L} \quad$ Applied load increment

$\Delta \delta \quad$ Vertical displacement increment

$\checkmark \quad$ Poisson's ratio

$\rho_{\mathrm{p}} \quad$ Plank density

$\sigma_{\mathrm{y}} \quad$ Yield stress

$v \quad$ Propagation velocity

Symbols:

a Distance between the load cell and nearest support

Ap Cross-section of the sample

b Section width

$F_{\max } \quad$ Maximum applied force

G Shear modulus

h Section depth

Ic Combined second moment of inertia about strong axis of the sample

Ip Second moment of inertia about strong axis of the sample

K Beam stiffness

L Plank length/Beam length/Distance between supports

$\mathrm{L}_{20}, \mathrm{~L}_{40} \quad$ Applied load at $20 \%$ and $40 \%$ of the maximum load

$\mathrm{M}_{\max } \quad$ Maximum bending moment

W Section modulus of the cross-section

Acronyms:

3D-FEM Three-dimensional finite element model

ART Acoustic Resonance Testing

EWP Engineered Wood Products 


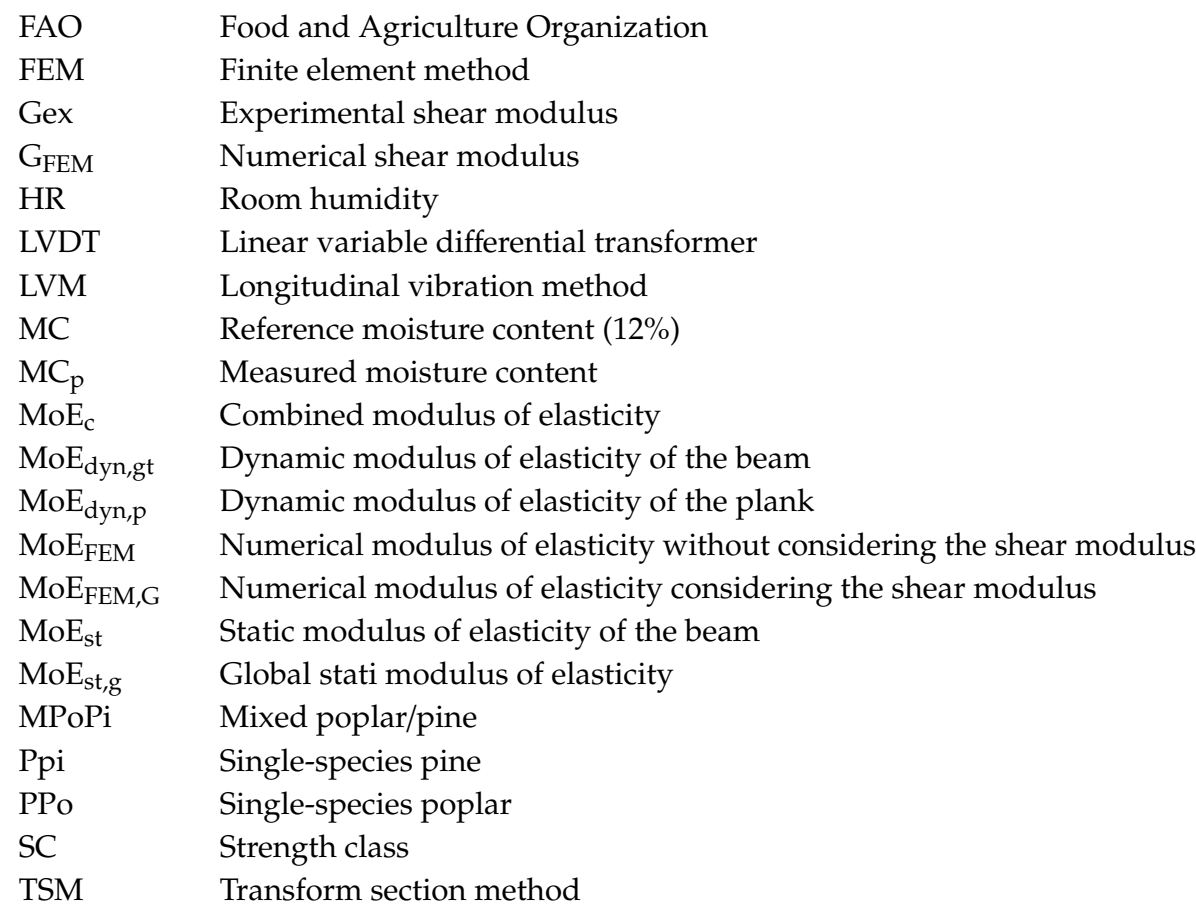

\section{References}

1. Foschi, R.O.; Barret, J.D. Glued-laminated beam strength: A model. J. Struct. Div. 1980, 106, 1735-1754.

2. Bodig, J.; Jayne, B.A. Mechanics of Wood and Wood Composites, 1st ed.; Van Nostrand Reinhold: New York, NY, USA; University of Michigan: Ann Arbor, MI, USA, 1982; 712p.

3. Thelandersson, S.; Larsen, H.J. Timber Engineering, 1st ed.; John Wiley \& Sons: West Sussex, UK, 2003; 456p.

4. Moody, R.C.; Liu, J.Y. Glued Structural Members. Wood Handbook: Wood as an Engineering Material, 1st ed.; USDA Forest Servies FPL: Madison, WI, USA, 1999; 509p.

5. Van Acker, J.C.; Defoirdt, N.; Van den Bulcke, J. Enhanced potential of poplar and willow for engineered wood products. In Proceedings of the 2nd Conference on Engineered Wood Products based on Poplar/Willow Wood (CEWPPW2), León, Spain, 8-10 September 2016.

6. Isebrands, I.; Richardson, J. Poplar and Willows: Trees for Society and the Environment, 1st ed.; CAB International and FAO (Food and Agriculture Organization of the United Nations): Rome, Italy, 2014; 699p.

7. Koller, W.; Lebedys, A. Poplar cultivation in Europa and Spain. In Proceedings of the II Poplar Symposium, Valladolid, Spain, 17-19 October 2019.

8. Biblis, E. Analysis of wood-fiberglass composite beams within and beyond the elastic region. Fresh Prod. J. $1965,15,81-88$.

9. Moody, R.C. Design criteria for large structural glued-laminated timber beams using mixed species of visually graded lumber. Res. Pap. FPL 1974, 236, 42.

10. Lepper, M.M.; Keena, F.J. Development of poplar-glued-laminated timber. I: Tensile strength and stiffness of poplar laminating stock. Can. J. Civ. Eng. 2011, 13, 445-459. [CrossRef]

11. Martins, C.; Dias, A.M.P.G.; Cruz, H. Using non-destructive testing to predict the mechanical properties of glued laminated poplar. Proc. Inst. Civ. Eng. Struct. Build. 2019, 172, 661-670. [CrossRef]

12. Castro, G.; Paganini, F. Mixed glued laminated timber of poplar and Eucalyptus grandis clones. Holz Roh Werkst. 2003, 61, 291-298. [CrossRef]

13. Tomasi, R.; Parisi, M.A.; Piazza, M. Ductile design of glued-laminated timber beams. Pract. Period. Struct. Des. Constr. 2009, 14, 113-122. [CrossRef]

14. Hernandez, R.; Davalos, J.F.; Sonti, S.S.; Kim, Y.; Moody, R.C. Strength and stiffness of reinforced yellow-poplar glued-laminated beams. Res. Pap. FPL 1997, 236, 28.

15. Dewi, S.M.; Soehardjono, A. Performance of glue laminated timber beams composed of sengon wood (Albizia falcatara) and coconut wood (Cocos nucifera) with nylon-threads reinforcement. In Proceedings of the 4th 
International Conference on Rehabilitation and Maintenance in Civil Engineering (ICRMCE 2018), Baru, Indonesia, 11-12 July 2018.

16. Mohamad, W.H.W.; Bhkari, N.M.; Ahamad, Z. Bending and bonding properties of mixed-species glued laminated timber from merpauh, jelutong and sesendok. J. Teknol. 2019, 81, 165-170. [CrossRef]

17. Martins, C.; Dias, A.M.P.G.; Cruz, H. Blue gum: Assessment of its potential for load bearing structures. In Proceedings of the 7th International Conference on Hardwood Processing (ISCHP 2019), Delft, The Netherlands, 28-30 August 2019.

18. Baño, V.; Godoy, D.; Figueredo, D.; Vega, A. Characterization and Structural Performance in Bending of CLT Panels Made from Small-Diameter Logs of Loblolly/Slash Pine. Materials 2018, 11, 2436. [CrossRef] [PubMed]

19. Shim, K.; Kim, K.; Park, J. Improvement of prediction accuracy of glulam modulus of elasticity by considering neutral axis shift in bending. Wood Fiber Sci. 2009, 41, 90-96.

20. Brancheriau, L.; Bailleres, H. Natural vibration analysis of clear wooden beams: A theoretical review. Wood Sci. Technol. 2002, 36, 347-365. [CrossRef]

21. Cirad. Non-Destructive Testing of Wood. Available online: https://www.picotech.com/library/applicationnote/non-destructive-testing-of-wood (accessed on 31 May 2020).

22. Baño, V.; Arriaga, F.; Soilan, A.; Guaita, M. Prediction of bending load capacity of timber beams using a finite element method simulation of knots and grain deviation. Biosyst. Eng. 2011, 109, 241-249. [CrossRef]

23. Gao, Y.; Wu, Y.; Zhu, X.; Zhu, L.; Zhiming, Y.; Wu, Z. Numerical Analysis of the Bending Properties of Cathay Poplar Glulam. Materials 2015, 8, 7059-7073. [CrossRef] [PubMed]

24. Timber Structures-Structural Timber and Glued Laminated Timber-Determination of some Physical and Mechanical Properties; Asociacion Española de Normalizacion: Madrid, Spain, 2012; UNE-EN 408:2011+A1:2012.

25. Structural Timber-Determination of Characteristic Values of Mechanical Properties and Density; Asociacion Española de Normalizacion: Madrid, Spain, 2019; UNE-EN 384:2016 + A12019.

26. Timber Structures_-Glued Laminated Timber and Glued Solid Timber-Requirements; Asociacion Española de Normalizacion: Madrid, Spain, 2013; UNE-EN 14080:2013.

27. Structural Timber-Strength Classes; Asociacion Española de Normalizacion: Madrid, Spain, 2010; UNE-EN 338:2010.

28. Mallick, P. Composites Engineering Handbook, 1st ed.; CRC Press: Boca Ratón, FL, USA, 1997; 1264p.

29. Code-Aster. Available online: http://www.code-aster.org (accessed on 31 May 2020).

30. Laursen, T.A. Computational Contact and Impact Mechanics, 1st ed.; Springer: Berlin, Germany, 2002; 472p.

31. Bravo, R.; Pérez-Aparicio, J.L.; Laursen, T.A. An energy consistent frictional dissipating algorithm for particle contact problems. Int. J. Num. Meth. Eng. 2012, 92, 753-781. [CrossRef]

32. Nour-Omid, B.; Wriggers, P. A note on the optimum choice for penalty parameters. Commun. Appl. Num. Methods 1987, 3, 581-585. [CrossRef]

33. Rescalvo, F.; Morillas, L.; Valverde-Palacios, I.; Gallego, A. Acoustic emission in I-214 poplar wood under compressive loading. Eur. J. Wood Prod. 2020. [CrossRef]

(C) 2020 by the authors. Licensee MDPI, Basel, Switzerland. This article is an open access article distributed under the terms and conditions of the Creative Commons Attribution (CC BY) license (http://creativecommons.org/licenses/by/4.0/). 